\title{
Determination of Hesperetin in Pericarpium Citri Reticulatae and Human Serum Using Flow Injection Chemiluminescence
}

\author{
Jiajia Wang, ${ }^{1}$ Xijuan Tan, ${ }^{1}$ Xin Li, ${ }^{1,2}$ Jiangman Liu, ${ }^{1}$ and Zhenghua Song1 \\ ${ }^{1}$ Key Laboratory of Synthetic and Natural Functional Molecule Chemistry of Ministry of Education, \\ College of Chemistry and Materials Science, Northwest University, Xi'an 710069, China \\ ${ }^{2}$ Shaanxi General Team of China Construction Materials and Geological Prospecting Center, Xi'an 710003, China
}

Correspondence should be addressed to Zhenghua Song, songzhenghua@hotmail.com

Received 11 March 2012; Accepted 6 May 2012

Academic Editors: M. E. Diaz-Garcia, P. Kingshott, M. Özgür, and M. L. Villarreal

Copyright ( $) 2012$ Jiajia Wang et al. This is an open access article distributed under the Creative Commons Attribution License, which permits unrestricted use, distribution, and reproduction in any medium, provided the original work is properly cited.

\begin{abstract}
A sensitive chemiluminescence (CL) method for the determination of hesperetin at nanogram levels was first presented. It was based on the inhibitory effect of hesperetin on luminol-dissolved oxygen CL reaction in a flow injection system. The decrements of CL intensity were logarithm over the concentrations of hesperetin in a range of 0.5 to $1000 \mathrm{ng} \mathrm{mL}^{-1}$, with a detection limit of $0.2 \mathrm{ng} \mathrm{mL}^{-1}(3 \sigma)$ and the relative standard deviations lower than $2.1 \%$. At a flow rate of $2.0 \mathrm{~mL} \mathrm{~min}^{-1}$, the whole determining performance including sampling and washing could be accomplished in $30 \mathrm{~s}$, giving a sampling efficiency of $120 \mathrm{~h}^{-1}$. The proposed method was applied successfully to the direct hesperetin determination in human serum with recoveries from 97.0 to $106.6 \%$, and indirect hesperidin quantification in $2.5 \mathrm{~g}$ pericarpium citri reticulatae showing that the content is $8.1 \pm 0.2 \%$. The possible CL mechanism of luminol-dissolved oxygen-hesperetin reaction was also discussed in detail.
\end{abstract}

\section{Introduction}

Hesperetin (5, 7, $3^{\prime}$-trihydroxy-4'-methoxy-flavanone, Figure 1), a bioflavonoid compound with glycosidic hesperidin as its natural existing form which is abundant in citrus fruits including lemon, lime (Citrus aurantifolia), and mandarin (Citrusreticulata) [1], possesses a wide spectrum of biological activities such as antiplatelet, anti-inflammatory, antioxidant and neuroprotective activities [2-5]. Since reported on the clinical application in attenuating capillary permeability in 1945 [6], there has been a growing interest in the pharmacological studies of hesperetin [7-10].

Methods previously employed for the determination of hesperetin involve high performance liquid chromatography (HPLC) with UV or MS detector [11-13], gas chromatography (GC) with MS detector [14], and micellar electrokinetic capillary chromatography (MEKC) with UV detector [15]. So far, no flow injection chemiluminescence (FI-CL) method has been reported on the determination of hesperetin.

In this work, it was found that hesperetin could inhibit the CL intensity from luminol-dissolved oxygen reaction, and the CL intensity decrements were logarithm over hesperetin concentrations ranging from 0.5 to $1000 \mathrm{ng} \mathrm{mL}^{-1}$, with a detection limit (LOD) of $0.2 \mathrm{ng} \mathrm{mL}^{-1}(3 \sigma)$ and the relative standard deviations (RSDs) lower than $2.1 \%$. At a flow rate of $2.0 \mathrm{~mL} \mathrm{~min}^{-1}$, the whole analysis procedure including sampling and washing could be accomplished in $30 \mathrm{~s}$, offering the sampling efficiency of $120 \mathrm{~h}^{-1}$. This proposed method was employed successfully to directly determine hesperetin in human serum samples with recoveries of $97.0-106.6 \%$, and indirectly measure the hesperidin in $2.5 \mathrm{~g}$ pericarpium citri reticulatae (PCR) with content of $8.1 \pm 0.2 \%$. The possible CL mechanism of luminol-dissolved oxygen-hesperetin reaction was also given.

\section{Experimental}

2.1. Reagents. All chemicals were of analytical reagent grade. Deionized water purified in a Milli-Q system (Millipore, Bedford, MA, USA) was used throughout. Luminol (Fluka, Biochemika, Switzerland) was purchased from Xi'an Medicine Purchasing and Supply Station, China. Luminol $\left(2.5 \times 10^{-2} \mathrm{~mol} \mathrm{~L}^{-1}\right)$ stock solution was prepared in $1.0 \times$ $10^{-1} \mathrm{~mol} \mathrm{~L}^{-1} \mathrm{NaOH}$ solution. Hesperetin was supplied by 


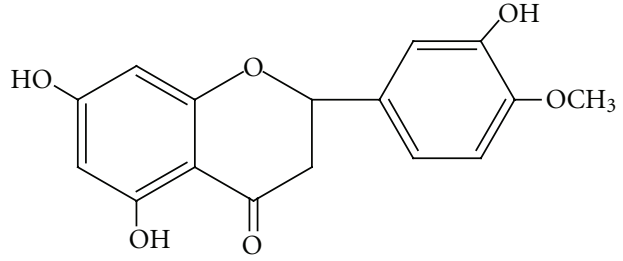

FIGURE 1: Structure of hesperetin.

Shaanxi Entry-Exit Inspection and Quarantine Bureau (Shaanxi, China). Hesperetin stock solution $\left(10 \mu \mathrm{g} \mathrm{mL} L^{-1}\right)$ was prepared in ethanol and stored at $4^{\circ} \mathrm{C}$. The working standard solutions of hesperetin were prepared daily from the above stock solution by appropriate dilution as required.

2.2. Apparatus. The FI-CL system (Xi'an Remax Analysis Instrument Co. Ltd., Xi'an, China) was depicted in Figure 2. The apparatus includes a sampling system (IFFM-E), a CL detector (IFFS-A), and a recorder (a computer with IFFME client system). The sampling system provides a peristaltic pump to propel all solutions into the flow lines, and a six-way valve with loops of $100 \mu \mathrm{L}$ to quantitatively inject luminol. The CL detector, which is placed inside a black box for precluding the interference from ambient light, contains a flow cell and a photomultiplier tube (PMT). The flow cell, which locates closely to the PMT, is a colorless glass tube $(15 \mathrm{~cm}, 1.0 \mathrm{~mm}$ i.d.) with a spiral disk shape $(2.0 \mathrm{~cm}$ i.d.). The CL signal from the flow cell was directly detected by the PMT without wavelength discrimination and the output was recorded on the computer. Polytetrafluoroethylene (PTFE) tubing $(1.0 \mathrm{~mm}$ i.d.) is used to carry all the reagents.

2.3. General Procedures. As shown in Figure 2, the solutions were propelled on each line at a constant rate of

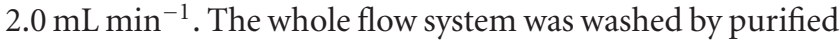
water until a stable baseline was recorded. Luminol $(100 \mu \mathrm{L})$ was then injected into the flow line via the six-way value, and merged with the stream of hesperetin. Thereafter, the mixed solution was delivered into the CL cell, and the CL signal was detected by PMT. The concentrations of hesperetin could be quantified based on the decrements of CL intensity $\left(\Delta \mathbf{I}_{\mathrm{CL}}=\right.$ $\mathbf{I}_{0}-\mathbf{I}_{\mathbf{s}}$ ), where $\mathbf{I}_{\mathbf{0}}$ and $\mathbf{I}_{\mathbf{s}}$ were CL signals in the absence and presence of hesperetin, respectively.

\subsection{Sample Preparation}

2.4.1. Treatment of PCR Samples. Hesperidin in PCR (the dried ripe pericarp of Citrus reticulata Blanco) from local market was transferred to hesperetin according to published method with some minor modifications $[16,17] .2 .5 \mathrm{~g}$ PCR were ground into thin powder and transferred into a beaker. $20 \mathrm{~mL}$ boiling water and $15 \mathrm{~mL}$ saturated lime water were added in. Then the $\mathrm{pH}$ of the solution was adjusted to 1213 using $\mathrm{NaOH}$ solution $\left(2.5 \mathrm{~mol} \mathrm{~L}^{-1}\right)$. After dunking for 18 hours, the solution was filtered through an ordinary filter paper and $\mathrm{HCl}$ was introduced into the filtrated solution with final concentration of $2.5 \mathrm{~mol} \mathrm{~L}^{-1}$. Thereafter, the mixture solution was treated in water bath of $100^{\circ} \mathrm{C}$ for $60 \mathrm{~min}$. Then suitable aliquots from above solution were taken for the determination.

2.4.2. Preparation of Spiked Human Serum Samples. Human serum samples from healthy volunteers were provided by the Hospital of Northwest University. The spiked samples were prepared by adding known quantities of hesperetin into $0.1 \mathrm{~mL}$ of each serum samples. After homogenization, the spiked serum samples with appropriate dilution were taken for hesperetin determination.

\section{Results and Discussion}

3.1. Relative CL Intensity-Time Profile. The relative CL intensity-time profile of luminol-dissolved oxygen-hesperetin was given in Figure 3 (The concentrations of luminol and $\mathrm{NaOH}$ were $2.5 \times 10^{-5}$ and $2.5 \times 10^{-2} \mathrm{~mol} \mathrm{~L}^{-1}$, resp.). It can be seen that the CL intensity of luminol-dissolved oxygen reaction reached the maximum of 211 at $5 \mathrm{~s}$ and then vanished in the following $20 \mathrm{~s}$; while in the presence of $100 \mathrm{ng} \mathrm{mL}^{-1}$ hesperetin, the maximum CL intensity remarkably decreased from 211 to 120 by $43.1 \%$.

\subsection{Optimum Experimental Conditions for the Determination} of Hesperetin. The effect of luminol concentration on the CL intensity was investigated over a range of $1.0 \times 10^{-7}$ to $1.0 \times$ $10^{-4} \mathrm{~mol} \mathrm{~L}^{-1}$, and $2.5 \times 10^{-5} \mathrm{~mol} \mathrm{~L}^{-1}$ luminol was selected as the optimum concentration giving a stable and strong $\mathrm{CL}$ intensity. Considering the nature of luminol CL reaction favoring in alkaline medium, $2.5 \times 10^{-2} \mathrm{~mol} \mathrm{~L}^{-1} \mathrm{NaOH}$ was added into the solution to enhance the CL intensity.

The effect of flow rate and mixing tube lengths was also examined. $2.0 \mathrm{~mL} \mathrm{~min}^{-1}$ flow rate and $5.0 \mathrm{~cm}$ mixing tube length were chosen in the subsequent experiments as a good compromise of sensitivity, reagent consumption, and reproducibility.

3.3. Performance of Hesperetin Measurement. Under the optimum experimental conditions given above, the standard solutions of hesperetin were determined. It was found that the CL intensity decrements were linear with the logarithm of hesperetin concentrations ranging from 0.5 to $1000 \mathrm{ng} \mathrm{mL}^{-1}$, giving the calibration equation of $\Delta \mathbf{I}_{\mathrm{CL}}=15.8 \ln \mathrm{C}_{\text {hesperetin }}+$ $28.9\left(R^{2}=0.994\right)$ with LOD of $0.2 \mathrm{ng} \mathrm{mL}^{-1}(3 \sigma)$ and RSDs $<2.1 \%$. At a flow rate of $2.0 \mathrm{~mL} \mathrm{~min}^{-1}$, one analyzing cycle of hesperetin determination including sampling and washing could be accomplished in $30 \mathrm{~s}$, which offered the sampling efficiency of $120 \mathrm{~h}^{-1}$, accordingly.

3.4. Interference Studies. The interference of potentially interfering species were tested by adding increasing amounts of interfering substance to the standard solution of hesperetin $\left(10 \mathrm{ng} \mathrm{mL}^{-1}\right)$ and the error was controlled at $5 \%$ level. The tolerable concentrations of interfering species were $100 \mu \mathrm{g} \mathrm{mL} \mathrm{m}^{-1}$ for $\mathrm{NO}_{3}{ }^{-}, \mathrm{Ac}^{-}, \mathrm{SO}_{4}{ }^{2-}$, ethanol and glucose, $10 \mu \mathrm{g} \mathrm{mL}^{-1}$ for $\mathrm{NH}_{4}^{+}, \mathrm{Mg}^{2+}$ and $\mathrm{Ca}^{2+}, 500 \mathrm{ng} \mathrm{mL}^{-1}$ for uric acid, $300 \mathrm{ng} \mathrm{mL}^{-1}$ for rutin, and $10 \mathrm{ng} \mathrm{mL}^{-1}$ for quercetin. Compounds abundant in human serum such as 


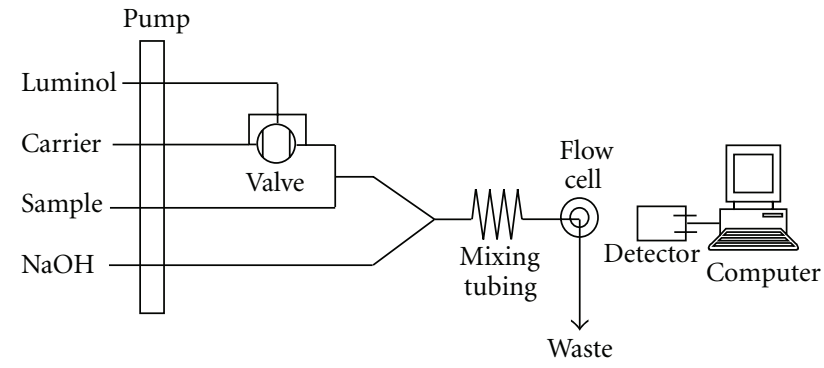

FIGURE 2: Schematic diagram of the FI-CL system for the determination of hesperetin.

TABLE 1: Results of hesperidin in PCR $(n=6)$.

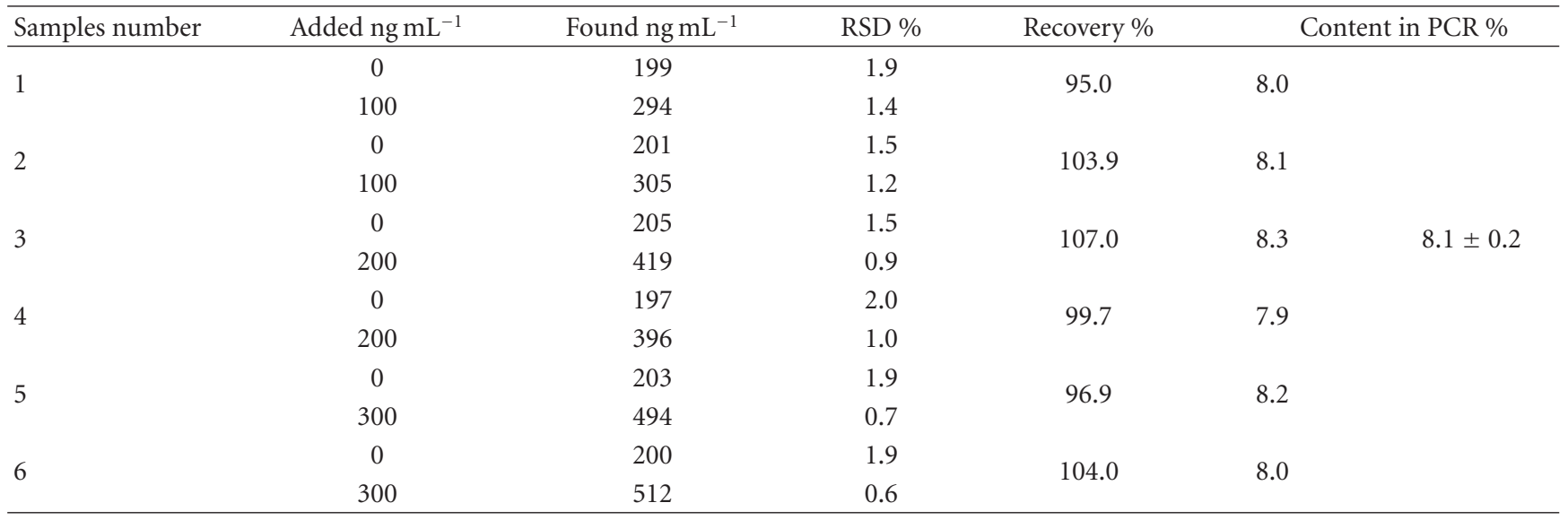

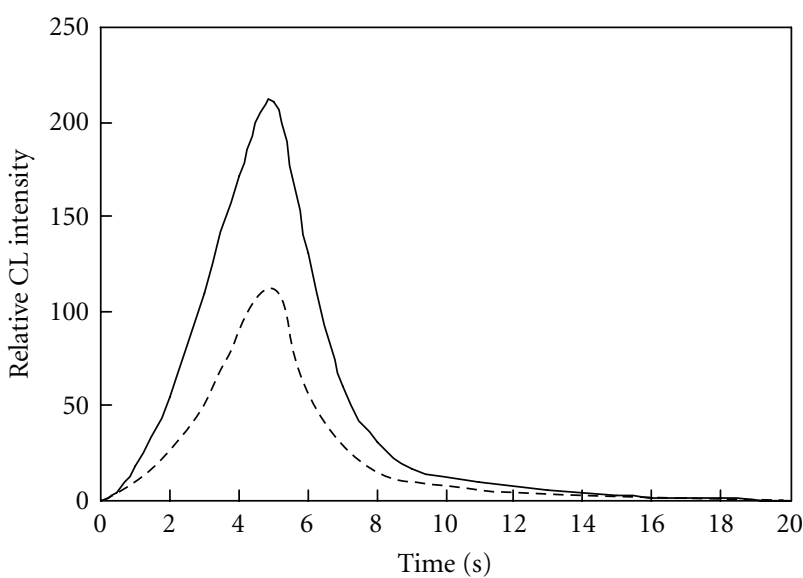

FIgURe 3: Relative CL intensity: time profile of different reactions. Luminol: $25 \mu \mathrm{mol} \mathrm{L}^{-1}$; hesperetin: $100 \mathrm{ng} \mathrm{mL}{ }^{-1}$; $\mathrm{NaOH}$ : $25 \mathrm{mmol} \mathrm{L}^{-1}$. Solid line: luminol-dissolved oxygen reaction; Dash line: luminol-dissolved oxygen-hesperetin reaction.

salts, lipids, and proteins had no obvious interference for the determination of hesperetin at nanogram levels.

\subsection{Possible Mechanism of Luminol-Dissolved Oxygen-Hesper-} etin CL Reaction. The possible mechanism of luminoldissolved oxygen-hesperetin reaction was discussed in detail. Firstly, the CL emission spectrum showed that the maximum
CL emission wavelength was at $425 \mathrm{~nm}$. This result suggested that luminol could react with dissolved oxygen to yield ${ }^{\bullet} \mathrm{O}_{2}{ }^{-}$ radicals and be oxidized subsequently to excited 3 -aminophthalate by the produced ${ }^{\bullet} \mathrm{O}_{2}{ }^{-}$radicals, with $\mathrm{CL}$ signals emitted in high $\mathrm{pH}$ medium $\left(0.025 \mathrm{~mol} \mathrm{~L}^{-1} \mathrm{NaOH}\right)$ [18]. Additionally, the UV spectra of luminol had no obvious change in the presence of hesperetin, which demonstrated that there was no interaction between luminol and hesperetin. Furthermore, the CL intensities generated by online ultrasonically degassed solutions decreased compared to that generated by the general solutions, indicating that hesperetin could react with ${ }^{\circ} \mathrm{O}_{2}{ }^{-}$radicals. The possible $\mathrm{CL}$ mechanism of luminol-dissolved oxygen-hesperetin reaction can be explained as that the anti-oxidant hesperetin can react with the yielded ${ }^{\bullet} \mathrm{O}_{2}{ }^{-}$radicals, which reduced the concentrations of ${ }^{\bullet} \mathrm{O}_{2}{ }^{-}$radicals leading to obvious inhibition of CL intensity from luminol-dissolved oxygen reaction.

\section{Application}

4.1. Indirect Determination of Hesperidin in PCR. $2.5 \mathrm{~g}$ PCR were pretreated by the modified method which was described in the experimental section and then suitable aliquots from above prepared samples were taken for the indirect determination of hesperidin. In order to evaluate the validity of the proposed method, recovery studies were carried out and the results were listed in Table 1, with recoveries from 95.0 to $107.0 \%$ and RSDs $<2.0 \%$. The contents of hesperidin 
TABLE 2: Hesperetin determination in spiked human serum samples $(n=6)$.

\begin{tabular}{|c|c|c|c|c|c|}
\hline Samples number & Added $\mathrm{ng} \mathrm{mL}^{-1}$ & Found $\mathrm{ng} \mathrm{mL} \mathrm{mL}^{-1}$ & RSD \% & Recovery \% & Proposed method/spiked $\mu \mathrm{g} \mathrm{mL} \mathrm{mL}^{-1}$ \\
\hline \multirow{2}{*}{1} & 0 & 19 & 1.5 & \multirow{2}{*}{97.0} & \multirow{2}{*}{$9.7 / 10.0$} \\
\hline & 20 & 39 & 1.0 & & \\
\hline \multirow{2}{*}{2} & 0 & 21 & 1.4 & \multirow{2}{*}{106.6} & \multirow{2}{*}{$10.6 / 10.0$} \\
\hline & 20 & 43 & 0.9 & & \\
\hline \multirow{2}{*}{3} & 0 & 20 & 1.6 & \multirow{2}{*}{98.2} & \multirow{2}{*}{$9.8 / 10.0$} \\
\hline & 20 & 39 & 1.0 & & \\
\hline \multirow{2}{*}{4} & 0 & 21 & 1.3 & \multirow{2}{*}{102.4} & \multirow{2}{*}{$10.5 / 10.0$} \\
\hline & 30 & 52 & 0.8 & & \\
\hline \multirow{2}{*}{5} & 0 & 20 & 1.5 & \multirow{2}{*}{97.0} & \multirow{2}{*}{$9.7 / 10.0$} \\
\hline & 30 & 49 & 0.9 & & \\
\hline \multirow{2}{*}{6} & 0 & 21 & 1.6 & \multirow{2}{*}{103.7} & \multirow{2}{*}{$10.3 / 10.0$} \\
\hline & 30 & 52 & 0.8 & & \\
\hline
\end{tabular}

TABLE 3: Comparison of different methods for hesperetin determination.

\begin{tabular}{|c|c|c|c|c|}
\hline Methods & Linear range $\mathrm{ng} \mathrm{mL}^{-1}$ & LOD $\mathrm{ng} \mathrm{m}^{-1}$ & Samples & References \\
\hline MEKC-UV & $2.0 \times 10^{4} \sim 6.0 \times 10^{5}$ & 6000 & Propolis & {$[15]$} \\
\hline \multirow[t]{2}{*}{ HPLC-UV } & $5.0 \times 10^{2} \sim 1.0 \times 10^{5}$ & 500 & $\begin{array}{l}\text { Human urine } \\
\text { Rat urine }\end{array}$ & {$[13]$} \\
\hline & $2.5 \times 10^{2} \sim 2.5 \times 10^{4}$ & 100 & Human urine & {$[12]$} \\
\hline GC-MS & $2.0 \sim 3.0 \times 10^{2}$ & 2.0 & $\begin{array}{l}\text { Human plasma } \\
\text { Human urine }\end{array}$ & {$[14]$} \\
\hline HPLC-MS/MS & $5.0 \sim 1.0 \times 10^{3}$ & 0.5 & Rat plasma & {$[11]$} \\
\hline FI-CL & $5.0 \times 10^{-1} \sim 1.0 \times 10^{3}$ & 0.2 & $\begin{array}{c}\text { PCR } \\
\text { Human serum }\end{array}$ & This study \\
\hline
\end{tabular}

in PCR were $7.9-8.3 \%$, which were in the reported range of $3.8 \%$ to $12.1 \%$ by HPLC [19].

\subsection{The Determination of Hesperetin in Spiked Human Serum} Samples. Hesperetin in the spiked serum samples prepared in the experimental section were measured, and the results were listed in Table 2. It can be seen that the recoveries of hesperetin were $97.0-106.6 \%$ and the RSDs were less than $1.7 \%$, which confirmed the applicability of this method to determine hesperetin in biological samples.

\section{Conclusion}

A simple and rapid CL method for the determination of hesperetin at nanogram levels was proposed for the first time. A comparison of the presented FI-CL method and the previously reported methods for the determination of hesperetin was given in Table 3 , showing this proposed method offered prominent advantages of wide linear range, lower detection limit, and analytical sensitivity. The satisfactory results of indirect hesperidin quantification in PCR and hesperetin determination in human serum samples confirmed the promise of this proposed method for further pharmacological and clinical research.

\section{Acknowledgments}

The authors gratefully acknowledge the financial support from the NWU Graduate Innovation and Creativity Funds (no. 09YZZ45 and no. 10YZZ29) and the open fund from the Key Laboratory of Synthetic and Natural Functional Molecule Chemistry of Ministry of Education, China.

\section{References}

[1] F. A. Tomás-Barberán and M. N. Clifford, "Flavanones, chalcones and dihydrochalcones-nature, occurrence and dietary burden," Journal of the Science of Food and Agriculture, vol. 80, no. 7, pp. 1073-1080, 2000.

[2] Y. R. Jin, X. H. Han, Y. H. Zhang et al., "Antiplatelet activity of hesperetin, a bioflavonoid, is mainly mediated by inhibition of PLC- $\gamma 2$ phosphorylation and cyclooxygenase-1 activity," Atherosclerosis, vol. 194, no. 1, pp. 144-152, 2007.

[3] O. Benavente-García and J. Castillo, "Update on uses and properties of citrus flavonoids: new findings in anticancer, cardiovascular, and anti-inflammatory activity," Journal of Agricultural and Food Chemistry, vol. 56, no. 15, pp. 61856205, 2008.

[4] P. P. Trivedi, S. Kushwaha, D. N. Tripathi, and G. B. Jena, "Cardioprotective effects of hesperetin against doxorubicininduced oxidative stress and DNA damage in rat," Cardiovascular Toxicology, vol. 11, no. 3, pp. 215-225, 2011. 
[5] J. S. Cho, "Antioxidant and neuroprotective effects of hesperidin and its aglycone hesperetin," Archives of Pharmacal Research, vol. 29, no. 8, pp. 699-706, 2006.

[6] H. Scarborough, "Observations on the nature of vitamin P and the vitamin P potency of certain foodstuffs," Biochemical Journal, vol. 39, pp. 271-278, 1945.

[7] A. Garg, S. Garg, L. J. D. Zaneveld, and A. K. Singla, "Chemistry and pharmacology of the Citrus bioflavonoid hesperidin," Phytotherapy Research, vol. 15, no. 8, pp. 655-669, 2001.

[8] S. Aranganathan, J. P. Selvam, and N. Nalini, "Effect of hesperetin, a citrus flavonoid, on bacterial enzymes and carcinogeninduced aberrant crypt foci in colon cancer rats: a dosedependent study," Journal of Pharmacy and Pharmacology, vol. 60, no. 10, pp. 1385-1392, 2008.

[9] S. Rainey-Smith, L. W. Schroetke, P. Bahia et al., "Neuroprotective effects of hesperetin in mouse primary neurones are independent of CREB activation," Neuroscience Letters, vol. 438, no. 1, pp. 29-33, 2008.

[10] Y. R. Jin, X. H. Han, Y. H. Zhang et al., "Hesperetin, a bioflavonoid, inhibits rat aortic vascular smooth muscle cells proliferation by arresting cell cycle," Journal of Cellular Biochemistry, vol. 104, no. 1, pp. 1-14, 2008.

[11] L. Tong, D. D. Zhou, J. Gao, Y. H Zhu, H. Sun, and K. S. Bi, "Simultaneous determination of naringin, hesperidin, neohesperidin, naringenin and hesperetin of Fractus aurantii extract in rat plasma by liquid chromatography tandem mass spectrometry," Journal of Pharmaceutical and Biomedical Analysis, vol. 58, pp. 58-64, 2012.

[12] K. Si-Ahmed, F. Tazerouti, A. Y. Badjah-Hadj et al., "Analysis of hesperetin enantiomers in human urine after ingestion of blood orange juice by using nano-liquid chromatography," Journal of Pharmaceutical and Biomedical Analysis, vol. 51, no. 1, pp. 225-229, 2010.

[13] J. A. Yáñez, X. W. Teng, K. A. Roupe, and N. M. Davies, "Stereospecific high-performance liquid chromatographic analysis of hesperetin in biological matrices," Journal of Pharmaceutical and Biomedical Analysis, vol. 37, no. 3, pp. 591-595, 2005.

[14] M. Spanakis, S. Kasmas, and I. Niopas, "Simultaneous determination of the flavonoid aglycones diosmetin and hesperetin in human plasma and urine by a validated GC/MS method: In vivo metabolic reduction of diosmetin to hesperetin," Biomedical Chromatography, vol. 23, no. 2, pp. 124-131, 2009.

[15] Y. Lu, C. Wu, and Z. Yuan, "Determination of hesperetin, cinnamic acid and nicotinic acid in propolis with micellar electrokinetic capillary chromatography," Fitoterapia, vol. 75, no. 3-4, pp. 267-276, 2004.

[16] X. B. Liu, Y. J. Li, X. Liu, and J. Cao, "Study of the extraction technology of hesperidin in Pericarpium Citri Reticulatae," Journal of GuiYang Medical College, vol. 31, no. 6, pp. 586-588, 2006.

[17] M. Y. Zhang, Q. L. Xia, J. R. Xing, Y. Yang, and S. M. Lu, "Acidcatalyzed hydrolysis of hesperetin," Food Science, vol. 31, no. 6, pp. 60-64, 2010.

[18] W. R. Seitz, "Determination of trace amounts of chromium (III) using chemiluminescence analysis," Analytical Chemistry, vol. 44, no. 6, pp. 957-963, 1972.

[19] G. Zheng, D. Yang, D. Wang, F. Zhou, X. Yang, and L. Jiang, "Simultaneous determination of five bioactive flavonoids in Pericarpium Citri Reticulatae from China by high-performance liquid chromatography with dual wavelength detection," Journal of Agricultural and Food Chemistry, vol. 57, no. 15, pp. 6552-6557, 2009. 


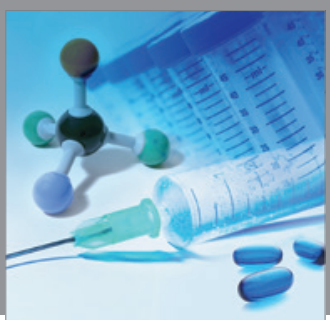

International Journal of

Medicinal Chemistry

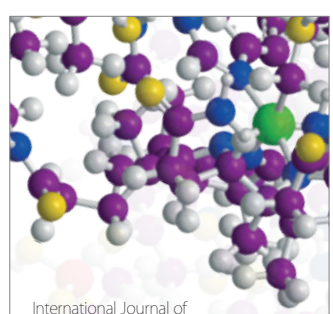

Carbohydrate Chemistry

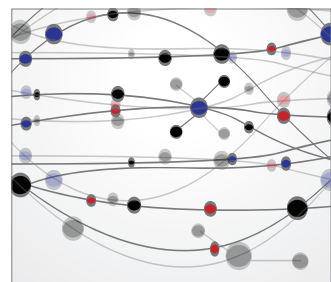

The Scientific World Journal
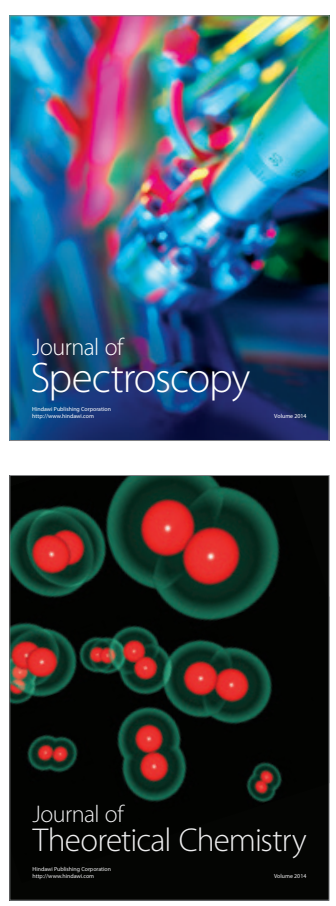
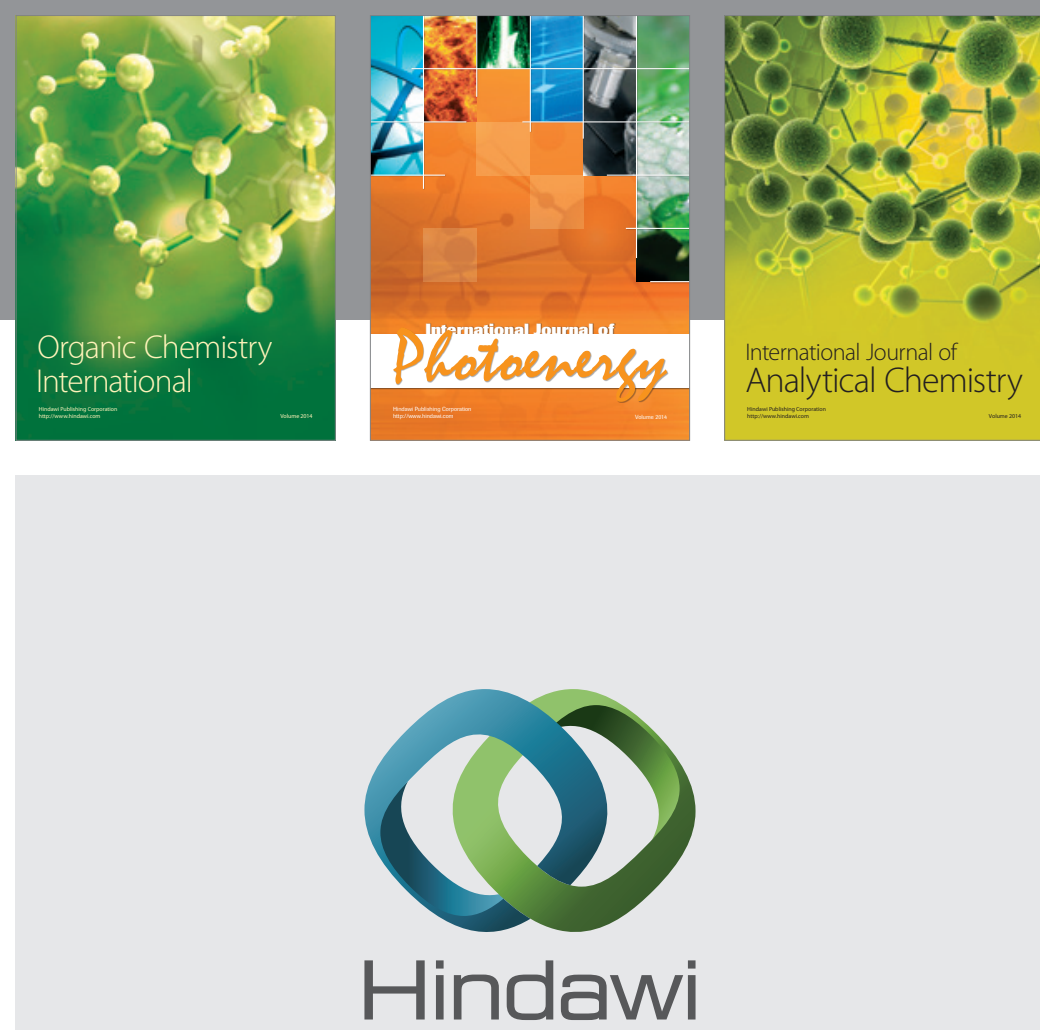

Submit your manuscripts at

http://www.hindawi.com
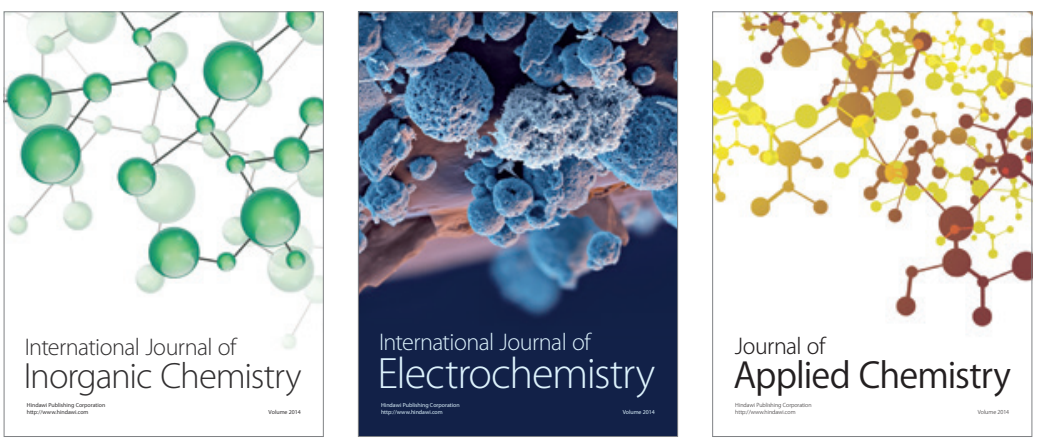

Journal of

Applied Chemistry
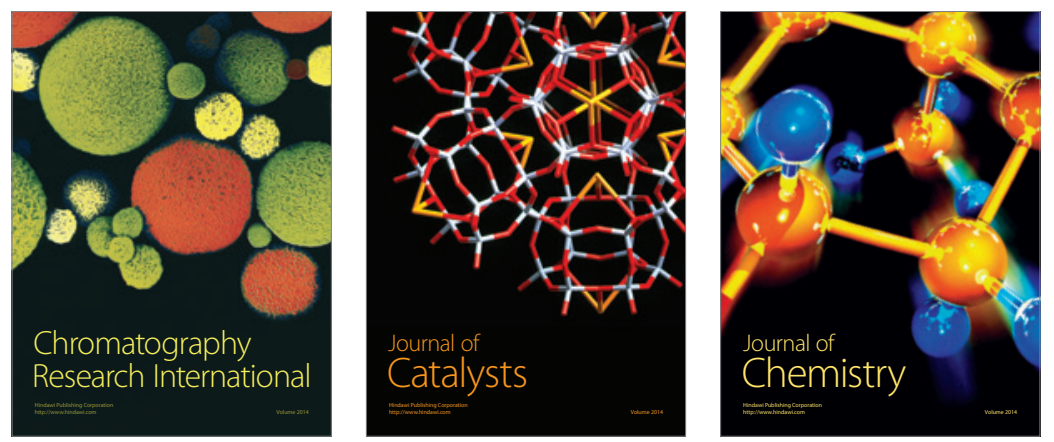
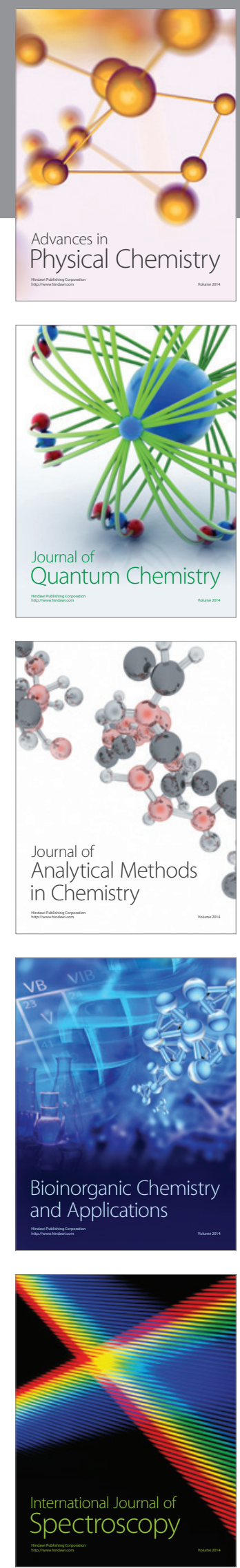